\title{
Memorias, dores e traumas: mulheres e ditadura em Tropical Sol da Liberdade
}

\author{
Memories, pain and trauma: \\ women and dictatorship in Tropical Sol da Liberdade \\ Camila Marchesan Cargnelutti \\ Unviersidade Federal de Santa Maria \\ Marcus Vinicius Reis \\ Universidade Federal do Sul e Sudeste do Pará \\ DOI: https://doi.org/10.5902/2176148537271
}

Resumo: Nesse estudo, articulando conceitos dos estudos de gênero, literatura, história e memória, analisamos Tropical sol da liberdade, de Ana Maria Machado. Publicado originalmente em 1988, em um contexto pós-ditatorial, o romance de Machado é construído em torno da temática da ditadura civil-militar no país (1964-1985), a partir da visão de personagens mulheres. Por meio da leitura crítica da narrativa, investigamos como a personagem principal, Lena, tenta apropriar-se da palavra para escrever uma peça teatral. Essa tentativa, no romance, configura-se como uma maneira de elaborar, narrar e externar seu passado traumático, fazendo parte da própria reconstrução identitária da personagem.

Palavras-chave: Memória. Trauma. Escrita. Mulheres. Ditadura.

Abstract: In this study, articulating concepts of gender studies, literature, history and memory, we analyze Tropical sol da liberdade, by Ana Maria Machado. Originally published in 1988, in a post-dictatorial context, Machado's novel is built around the theme of civilmilitary dictatorship in Brazil (1964-1985), from the view of female characters. Through critical reading of the narrative, we investigate how the main character, Lena, tries to appropriate the word to write a play. This attempt, in the novel, is configured as a way to elaborate, narrate and externalize his traumatic past, being part of the identity reconstruction of the character.

Keywords: Memory. Trauma. Writing. Women. Dictatorship. 


\section{Sobre a necessidade de novas formas de representação}

Assim como o conceito de mimesis e de representação percorreu significativas transformações desde a Antiguidade, passando pela Idade Média e pelo Renascimento, até chegar às várias correntes da Modernidade, também a forma de construção narrativa foi sendo alterada, conforme os novos

Camila

Marchesan

Cargnelutti

Marcus

Vinicius Reis tempos. Frente ao contexto catastrófico do século XX, o próprio gênero romance passou por mudanças profundas, de maneira a abrigar determinadas formas na tentativa de dar conta de apreender as mudanças e os horrores que estavam acontecendo. Se, anteriormente, o romance tradicional realista $^{1}$ caracterizava-se por elementos distintivos, como narração em terceira pessoa, onisciência do narrador, descrições baseadas na factualidade e na verossimilhança, apreensão do objeto em sua totalidade e construção de um discurso de leitura única, fechado, com início, meio e fim bem articulados, a partir do surgimento do romance contemporâneo moderno esses elementos passam a ser questionados e colocados em xeque ${ }^{2}$.

No romance moderno, o que predomina, em oposição ao romance tradicional, é justamente uma narração assentada no subjetivismo, uma estruturação fragmentada e não linear, com amplo uso de recursos metalinguísticos e com uma construção narrativa aberta, que permite uma pluralidade de versões sobre um determinado acontecimento ou objeto - e não uma verdade única e absoluta. Conforme explica Theodor Adorno (2003), ao abordar a questão do narrador no romance contemporâneo, essas mudanças relacionam-se ao próprio contexto em que surgem e à compreensão da impossibilidade de transformar em matéria literária a realidade, ou seja, à impossibilidade de dar conta de apreender literariamente o real. 0 século $\mathrm{XX}$, particularmente, foi palco de tantos horrores que "a permanente ameaça da catástrofe não permite mais a observação imparcial, e nem mesmo a imitação estética dessa situação" (ADORNO, 2003, p. 61).

Nesse sentido, simultaneamente a essas novas concepções, o século XX gera a necessidade de novas formas de representação, na tentativa de repensar a realidade e as relações humanas, assim como de apreendê-las literária e artisticamente. Sobre esse contexto, Márcio Seligmann-Silva (2009) afirma que, ainda que haja registro de atos literários testemunhais desde o século XVIII, foi no século XX que vimos

\footnotetext{
Fazemos referência, aqui, ao romance realista como forma (realismo) e não como período literário.

2 No capítulo "Reflexões sobre o romance moderno", do livro Texto/contexto, Rosenfeld (1969) aborda mais detalhadamente algumas particularidades do romance tradicional, assim como as mudanças observadas com o surgimento do romance moderno.
} 
aflorar e se fortalecer uma literatura com forte teor testemunhal. Segundo o autor, “o excesso de catástrofes impingidas pelas nossas próprias mãos - nesse século cerca de 140 milhões morreram por atos bárbaros em guerras, genocídios e perseguições - gerou uma necessidade de testemunho" (SELIGMANN-SILVA, 2009, p. 133).

No artigo "Narrar o trauma: a questão dos testemunhos de catástrofes históricas", Seligmann-Silva (2008) reflete sobre algumas das principais características desse teor testemunhal apontado em uma ampla literatura do século XX. Dentre elas, estão a sua origem marcada sob o signo do colapso e do trauma, assim como a própria impossibilidade de narração do inenarrável. Retomando produções como as de Dori Laub (1995) e Primo Levi (1988), Seligmann-Silva (2008, p. 65) ressalta que, em contextos de catástrofes e traumas, “a memória do trauma é

Memórias, dorese traumas sempre uma busca de compromisso entre o trabalho de memória individual e outro construído pela sociedade", ou seja, compreende a tarefa individual da narrativa do trauma baseada em memórias individuais e, simultaneamente, a sua componente coletiva. Essa confluência fundamenta-se, então, em um trabalho individual e particular de memória e outro que deve ser construído pela sociedade coletivamente, de maneira a constituir uma política de memória. Nesses trechos, o autor aborda, mais especificamente, "catástrofes históricas", como nos genocídios ou nas perseguições violentas e em massa a parcelas sociais específicas. No entanto, ressalvadas as particularidades e dimensões de cada contexto, suas reflexões também podem se estender a outros espaços, como em contextos latino-americanos. $\mathrm{Na}$ obra que analisaremos nesse estudo, Tropical sol da liberdade (1988), da escritora brasileira Ana Maria Machado, investigaremos as possibilidades da literatura de adentrar âmbitos que os discursos oficiais não alcançam e, dessa forma, narrar outras histórias sobre as violências, traumas, dores e memórias da ditadura civil-militar brasileira (1964-1985), com origem em sujeitos mulheres.

\section{As possibilidades da literatura de autoria feminina}

No âmbito da América Latina, o gênero literatura de testemunho surge na segunda metade do século XX, nascendo da "necessidade de se expressar a opressão dos grupos subalternos em um contexto de ferrenhas ditaduras nos Estados Nacionais latino-americanos" (ALÓS, 2009, p. 141; Cf. também ALÓs 2013, 2017a e 2017b). Esse gênero, aqui, se consolidou com obras como Si me permiten hablar..., testemunho da operária 
boliviana Domitila Barrios de Chungara à escritora e socióloga brasileira Moema Viezzer, publicado em 1977; e Me llamo Rigoberta Menchú y así me nació la conciencia, testemunho da líder indígena guatemalteca Rigoberta Menchú à historiadora e antropóloga venezuelana Elizabeth Burgos $^{3}$. Esses escritos são construídos a partir das inter-relações entre Camila elementos fictícios e factuais, entre a linguagem poética e a linguagem Marchesan referencial, e vinculam-se a histórias que não estão representadas nos Cargnelutti

Marcus discursos oficiais.

A partir da compreensão de que não existe uma forma única de Vinicius Reis ver as coisas, mas uma multiplicidade de possibilidades, a literatura de testemunho constitui-se como uma forma de abordar aquilo que a história muitas vezes silencia, e de construir novas versões, a partir de vozes que foram, de diversas formas, marginalizadas. Nesse sentido, a literatura de autoria feminina - e, particularmente, narrativas que são construídas a partir de memórias e de eventos traumáticos - configura-se também como um modo de abordar perspectivas de uma parcela da sociedade que foi historicamente marginalizada e amplamente silenciada.

A partir de narrativas escritas por mulheres, como em Tropical sol da liberdade, dá-se voz a suas perspectivas sobre o contexto político/histórico em que estão inseridas. Conforme explica Márcia Navarro (1995, p. 16), nesse processo há uma transformação: “em lugar de enfraquecer as narrativas por causa do tom 'feminino', dá a elas uma força renovada e uma originalidade adicional enquanto, ao mesmo tempo, subverte o cânone literário. $O$ 'feminino' então é transformado em uma perspectiva 'feminista"'. Dessa forma, a literatura de autoria feminina pode dar espaço a visões que foram historicamente marginalizadas, tanto na historiografia literária canônica, quantos nos discursos históricos tradicionais - perspectivas, muitas vezes, em discordância com essas narrativas hegemônicas. Ao mesmo tempo, a literatura de autoria feminina e os estudos teóricos e críticos a seu respeito impulsionam reflexões referentes aos processos discursivos que constituem essas hegemonias, assim como sua influência na memória e na história nacional, visibilizando vieses com origem em sujeitos considerados como a alteridade, o Outro.

3 Uma particularidade desses dois exemplos latino-americanos, e que os diferenciam dos testemunhos como o de Levi e Laub, citados anteriormente, diz respeito ao intermédio e convívio entre os discursos de dois sujeitos narradores, geralmente representados pelo editor e pela testemunha. Sobre essas questões, conferir o artigo de Valeria de Marco, intitulado "A literatura de testemunho e a violência de Estado", publicado em 2004. 
Tropical sol da liberdade, como constructo estético-cultural em consonância com esses posicionamentos, também manifesta, de variadas formas, representações dessa diferença. No romance, as mulheres (principalmente Lena e Amália, sua mãe) apropriam-se da narrativa literária como uma maneira de expressar suas próprias concepções e experiências vividas naquele período. Ao escrever sobre as mulheres, a literatura e a construção da irmandade nacional, Mary Louise Pratt (1994, p. 128) afirma que às mulheres sempre foi relegada a condição de "outras" para a nação, e que esse processo tem mudado nas últimas décadas a partir da "emergência atual do sujeito feminino na América Latina como político e histórico".

Dando visibilidade a novas perspectivas, muitas vezes em confronto com a versão tradicional ou oficial, a literatura de autoria fe-

Memórias, dorese traumas minina e, particularmente, a obra analisada na sequência, configura-se como um espaço para a expressão da diferença, da alteridade, da dissonância. Em Tropical sol da liberdade, a personagem principal, Lena, tenta elaborar e relatar, na forma de escrita de uma peça teatral baseada em testemunhos, seus traumas e dores relacionados ao passado ditatorial brasileiro. A apropriação da escrita pelas mulheres, nesse sentido, representa uma forma de narrar outras visões e outras histórias, baseadas em vivências e experiências femininas, como no caso de Tropical sol da liberdade. Por sua vez, essas novas perspectivas construídas a partir da literatura, muitas vezes, assumem uma posição de confronto em relação aos discursos oficiais, históricos ou literários, constituindo-se também como espaços fundamentais de resistência, de memória, de libertação e de empoderamento feminino.

\section{Entre memórias e dores, um sujeito em reconstrução}

Em Tropical sol da liberdade, Lena, jornalista e escritora, encontra-se em um momento de crise e procura a proteção da mãe e da casa da infância em uma tentativa de recuperar o prumo e reequilibrar-se. Exilada durante a ditadura civil-militar brasileira por suas ideologias e por seu envolvimento político, a personagem apresenta em seu corpo e em sua mente vestígios desse passado traumático e repressivo, que podem ser percebidos em diversas passagens da obra. Ao recolher-se à casa materna, Lena rememora constantemente o passado e alimenta o desejo de escrever parte de suas memórias através de uma peça de teatro. No entanto, a personagem está, momentaneamente, impossibilitada de fazê- 
-lo, por lapsos - que não são totalmente esclarecidos no romance - no equilíbrio, na fala e na escrita. Conforme a definição de Rosani Umbach (2013, p. 477), a personagem encontra-se "enferma da palavra", não conseguindo, no presente da narrativa, expressar por meio da escrita suas lembranças, seus traumas e suas dores.

Camila Essas dores, mais do que memórias conscientes de um passado Marchesan recente, são sentidas em todo o corpo da personagem, podendo estar reCargnelutti

Marcus lacionadas também ao atual estado de desequilíbrio físico de Lena, que apresenta quedas constantes e está fazendo um tratamento medicinal para o distúrbio. $\mathrm{O}$ estado de Lena pode ser relacionado à formulação de Aleida Assmann, retomada por Umbach (2008, p. 18), sobre "memória corporal" - "o corpo como repositório da memória de experiências traumáticas":

Falar em memórias da repressão implica, pois, referir-se não apenas a uma memória mental, desde sempre associada à consciência, ao caráter retrospectivo das lembranças e a conscientização voluntária do ocorrido; implica sobretudo referir-se a uma 'memória corporal', a qual abrange, na formulação de Aleida Assmann (1999), aquelas lembranças que não estão à disposição do livre arbítrio e por isso não podem ser manipuladas de acordo com a própria vontade. O corpo surge, então, como metáfora, como repositório da memória de experiências traumáticas. Fala-se de trauma quando uma lembrança armazenada pelo corpo está totalmente desvinculada da consciência: seria uma experiência corporalmente encapsulada, a qual se exprime através de sintomas e se subtrai a uma evocação recuperadora (UMBACH, 2008, p. 18).

Logo no início de Tropical sol da liberdade, Lena é apresentada como "apenas uma mulher machucada que precisava se fechar numa toca e ficar passando a língua nas feridas até cicatrizarem" (MACHADO, 1988, p. 12). As razões para o corpo machucado da personagem vão sendo delineadas ao longo da narrativa e envolvem, dentre outras, os traumas do exílio recente e o término de seu casamento. Lena sofre física e psicologicamente, e seu corpo é representado como um repositório dessas lembranças - tanto sua mente quanto seu corpo guardam a memória dos traumas e das dores do passado. Na sequência, é possível observar 
alguns excertos onde essas relações são exemplificadas, assim como termos que evidenciam as dores físicas e psicológicas que as memórias ainda causavam à personagem - "humilhada", "arrasada", "prostrada”, "barulhos lá de dentro", "areia ardente":

Sei que, muito provavelmente, eu estou caindo porque não estou conseguindo me manter de pé diante do que está acontecendo. Fico humilhada, arrasada, prostrada, sei lá... (MACHADO, 1988, p. 55).

Deixar vir as lembranças, peneirar, separar, implicava necessariamente sentir dor de novo. E encarar de frente. Agora, por Memórias, dores e exemplo, deitada no escuro, fingindo que queria dormir, fingindo traumas mais ainda, que não conseguia porque havia uns barulhos lá fora, Lena não podia mais fazer de conta que não ouvia os barulhos lá de dentro. E não eram só as lembranças das passeatas e dos dias jovens da ditadura, evocados pela conversa com a mãe. Essas eram as lembranças que ela catava e espalhava por cima do terreno, para disfarçar a areia ardente em que não queria pisar. Mas por baixo queimava, e ela sabia (MACHADO, 1988, p. 114).

Ao longo da narrativa de Machado, a personagem encontra-se em um impasse em sua trajetória: deseja esquecer as memórias dos traumas e, simultaneamente, sente a necessidade de relembrar o passado traumático e escancarar a dor - "e era principalmente da dor que ela precisava falar" (MACHADO, 1988, p. 162); “era demais. Lena não aguentaria continuar, sabia bem. 0 exílio acabou, a dureza acabou, o casamento acabou. Mas a dor continuava lá dentro, firme" (MACHADO, 1988, p. 210). Diante de tal situação, a personagem busca a escrita de uma peça de teatro como um recurso literário para falar de seus traumas e, de certa forma, lembrar e esquecer a dor. De acordo com Seligmann-Silva (2013, p. 133), o sobrevivente de eventos traumáticos deseja, através de seu relato, "não apenas gerar memória (e, se possível, justiça), mas também gerar o seu esquecimento". A partir do seu testemunho, Lena buscaria, além da memória e narração do trauma, uma espécie de esquecimento, no sentido de afastamento da dor. Para Seligmann-Silva (2013, p. 134), as vítimas necessitam "narrar, elaborar e esquecer" seus traumas e "querem esquecer porque são assombradas pelo sofrimento desses males e não para apagar as atrocidades e, muito menos, negar um sentimento de justiça". 
O impasse em que se encontra Lena, entre o desejo de lembrar e de esquecer, é agravado na narrativa de Tropical sol da liberdade, uma vez que a personagem está momentaneamente com um distúrbio relacionado ao seu equilíbrio. Somado ao trauma, há ainda a medicação que toma para o tratamento, o que dificulta - e muitas vezes imposCamila sibilita - a transposição de seus pensamentos para a palavra escrita: Marchesan "como tecer frases se o fio das palavras se rompe a toda hora, como Cargnelutti

Marcus carretilha quebrada na máquina de costura, embolando a linha e mordendo em seco?" (MACHADO, 1988, p. 82). Esse distúrbio, por sua vez, conforme abordado anteriormente, pode ser compreendido como uma consequência do passado traumático da personagem, que guarda em sua mente e em seu corpo as memórias da dor.

Por conta de seu distúrbio, Lena encontra-se constantemente com "medo de cair" - "faltava era coragem para experimentar e ousar dar o salto no escuro. Medo de voltar a cair. E não levantar mais" (MACHADO, 1988, p. 82); "mas se eu cair, quem cai sou eu, não é? Como se o senhor me animasse a atravessar uma pontezinha em cima de um abismo. Mas não é o senhor que atravessa... E se eu cair?" (MACHADO, 1988, p. 85). Pode-se perceber que a personagem sente medo de perder o prumo, desequilibrar-se, cair novamente e não mais conseguir erguer-se e, ao mesmo tempo, visualiza as possibilidades que parar com a medicação para esse transtorno e enfrentar seu passado podem trazer, principalmente no que se refere à sua capacidade de voltar a ter domínio sobre sua fala e sua escrita - sobre suas palavras. Do outro lado, como "recompensa" por enfrentar o abismo, estaria a escrita da peça de teatro baseada em suas memórias do exílio:

\footnotetext{
O pior era que do outro lado do abismo e da ponte estreita e perigosa também estava o embrião da peça e de todos os textos futuros. Impossível tentar escrever nessas condições. Lena sentia que mais cedo ou mais tarde ia ter que se decidir de uma vez por todas. Ou desistia de escrever, ou se arriscava a despencar. Mas ainda não tinha coragem (MACHADO, 1988, p. 86).
}

No entanto, para alcançar o "outro lado do abismo" e poder colocar em palavras suas memórias, seria preciso também encarar suas dores, recordar seus traumas, abrir-se para os outros através das letras. São esses os passos que Lena procura encontrar coragem e forças para dar, mas 
depara-se inevitavelmente com o medo de cair e o medo de rememorar, por todo o sofrimento que seu passado traumático ainda lhe traz - "o que ficava muito complicado era qualquer tentativa de botar para fora, de passar para as palavras, de tentar a viagem de dentro de si mesma para o outro [...]. Não conseguia. Mesmo falar, já era muito difícil. Escrever, então, no momento nem pensar" (MACHADO, 1988, p. 127).

A personagem encontra-se impossibilitada de escrever, com dificuldade de falar e, muitas vezes, com medo de rememorar. Consciente de seu estado atual, quando busca a proteção e a segurança da casa da infância, da mãe e da amendoeira do quintal para superar suas crises, Lena faz questão de não levar a máquina de escrever. No entanto, não consegue desfazer-se das visões, do delírio, da memória, do sonho e do pesadelo, carregados dentro de si mesma, como memórias do corpo e Memórias, dorese traumas da mente. Ao longo do romance, mesmo impossibilitada de transpor em palavras suas experiências traumáticas, Lena vê a escrita como um recurso para elaborar, lembrar e esquecer as memórias dolorosas. 0 desejo de escrever uma peça de teatro, já iniciada, que aborde algumas das experiências vividas no exílio, representa uma possibilidade de compartilhar, através das palavras, seu mundo interior com os outros.

Essa relação com a escrita presente no romance de Machado relaciona-se ao que Braunstein ([s.d.]) aborda no texto Sobrevivendo ao trauma. Conforme explica o autor, o trauma resiste à representação e, simultaneamente, exige a sua narração. Em outras palavras, "o trauma é o real impossível de simbolizar" ([s.d.], p. 8), e, ao mesmo tempo, necessita ser elaborado, representado, simbolizado - de maneira individual e também coletiva. Em Tropical sol da liberdade, essa tentativa angustia e machuca a personagem Lena ao longo de toda a obra; no entanto, mesmo assim, é vista como uma tarefa necessária para encontrar uma espécie de "salvação" para a personagem: "até mesmo as palavras que iam ser a ponte, o paraquedas para o salto no escuro, já estavam lá dentro também, embriões de frases, expressões gestadas, floração, germinando" (MACHADO, 1988, p. 128-129).

Ana Maria Machado, através de sua narrativa, abre espaço para a perspectiva de um gênero historicamente silenciado e marginalizado, possibilitando a abordagem de processos históricos, tal como regime ditatorial brasileiro, por um viés não contemplado pelos discursos hegemônicos e pela história oficial. Lena, de acordo com o narrador, deseja contar suas experiências e vivências relacionadas à ditadura a partir da 
“visão da periferia" (MACHADO, 1988, p. 33). Em contextos repressivos, o silenciamento e a exclusão reservada às mulheres são ainda mais acirrados, e suas histórias frequentemente são distorcidas, manipuladas e ocultadas por discursos oficiais.

Quando se tenta impedir de diversas formas a emergência de dis-

Camila

Marchesan

Cargnelutti

Marcus

Vinicius Reis cursos dissonantes, também desponta a tentativa de interromper processos de formação identitária de grupos vistos como o Outro, do ponto de vista do grupo de referência. As identidades, conforme Rita Schmidt (1998, p. 184), são como "movimentos contínuos/descontínuos das relações que sujeitos, comunidades, nações estabelecem imaginariamente com o outro, o que garante sua autoconstituição, e sua inserção dentro de certas condições sócio-históricas e discursivas", que, por sua vez, sustentam aquelas relações. As subjetividades e representações simbólicas da identidade configuram-se como espaços da ideologia, explicando o interesse - reforçado em contextos repressores - dos grupos hegemônicos nesses processos de coação das vozes da alteridade (SCHMIDT, 1998).

Nesses casos, como contraponto, o papel da memória sobressai-se como um lugar para a (re)construção identitária de grupos socialmente minoritários, conforme explica a pesquisadora:

[...] a memória, mais do que um simples arquivo classificatório de informação que reinventa o passado, é um referencial norteador na construção de identidades no presente. Em sua capacidade de manter e segurar o sentido, a memória atua por meio de seus efeitos, que tanto podem ser de lembrança e de renomeação, quanto de ruptura e de denegação do já-dito. Se a memória é, portanto, um fato essencial do processo cognitivo, inerente à construção de identidade, o discurso é o instrumento de (auto) conhecimento, através do qual o(s) ser(es) humano(s) se fazem sujeitos no campo da produção e das relações sociais (SCHMIDT, 1998, p. 184-185).

Assim como a memória é essencial no processo de constituição de identidades, o discurso produzido pelos seres humanos é o instrumento por meio do qual eles se tornam sujeitos. A tentativa de apropriação da narrativa pela personagem Lena, de Tropical sol da liberdade, para falar desde outro ângulo da história ditatorial brasileira representa muito mais que uma forma de questionamento dos discursos oficiais 
e de resistência frente a eles. 0 desejo - e a necessidade - que impulsionam e motivam Lena a escrever suas memórias é relatado em diversas passagens do romance, e representam, principalmente, uma possibilidade de contar uma história de silenciamento e desapropriação da voz feminina, desconstruindo a representação tradicional das mulheres e transformando-as em sujeitos de seus próprios discursos, de suas próprias identidades e de suas próprias histórias.

Como explica Navarro (1995, p. 14), ainda que não tenham essa intenção explícita, "quando as obras ficcionais incluem a mulher como sujeito e não como mero objeto do foco narrativo, elas não apenas desafiam ou tentam subverter a cultura patriarcal dominante mas também fornecem à mulher a voz adequada para falar por si mesma". Nesse processo, que está intrinsecamente relacionado ao ato de escrita literáMemórias, dorese traumas ria, configura-se a possibilidade de a mulher deixar de ser apenas um "outro", como objeto para ser visto e apreciado pelo sujeito masculino, para transformar-se em sujeito, adquirindo recursos e condições para ver, analisar e narrar a partir de sua própria perspectiva.

Segundo Regina Dalcastagnè (1996, p. 114), "reconstruir o vivido é refazer a história, recolocando nela personagens marginalizadas". Dessa forma, ocorre o que a pesquisadora chama de dupla reabilitação: "refaz-se aí a história dos vencidos e, dentro dessa história, recompõe-se o lugar da mulher". Essa dupla reabilitação, através da obra literária, que também pode ser entendida como um desejo de Lena ao narrar suas memórias da periferia, relaciona-se ao que Seligmann-Silva (2008) afirma a respeito da narrativa de testemunho por meio da literatura:

\footnotetext{
A narrativa teria [...] esse desafio de estabelecer uma ponte com "os outros", de conseguir resgatar o sobrevivente do sítio da outridade, de romper com os muros do Lager [campo de concentração]. A narrativa seria a picareta que poderia ajudar a derrubar este muro. [...] Narrar o trauma, portanto, tem em primeiro lugar este sentido primário de renascer (SELIGMANN-SILVA, 2008, p. 66).
}

Nesse processo vivenciado pela personagem, história, memória e literatura são inseparáveis e estão diretamente relacionadas à formação de identidades, tanto individuais quanto coletivas. Ao mesmo tempo em que vê na escrita a possibilidade de lembrar e esquecer os traumas, con- 
forme abordado anteriormente, pode-se perceber através da voz narrativa que Lena também apresenta aquilo que Seligmann-Silva (2008) chama de desejo de "renascer" do sobrevivente de eventos traumáticos, por meio do qual se manifesta seu anseio de reconstruir sua identidade e reconstituir-se como sujeito.

Camila

Em Tropical sol da liberdade, a protagonista encontra-se em um Marchesan dos "momentos mais difíceis que já tinha vivido, insegura, à procura Cargnelutti de si mesma" (MACHADO, 1988, p. 115) e sente que, de alguma forma, precisa encontrar forças e coragem para renascer, tal como uma fênix:

Marcus

Vinicius Reis

\begin{abstract}
A menina Lena não sabia o que era fênix. Só foi saber mais tarde, quando cresceu. E a mulher Lena pensava consigo mesma que era isso mesmo o que ela precisava ser, uma fênix. Em algum momento, teria que fazer isso, renascer integral. Como a cobra que sai inteira da pele velha, deixa para trás a casca vazia, e brota de dentro de si mesma, nova, guardando aquilo que era essencialmente. Não como a borboleta que sai do casulo sem conservar nada da lagarta que tinha sido antes. Renascer sem metamorfose, fiel a si mesma. Um desafio permanente. $\mathrm{O}$ de conseguir estar viva (MACHADO, 1988, p. 234).
\end{abstract}

No excerto acima, observa-se o desejo de renascimento, de transformação e de renovação da protagonista da obra, apesar das - e com as - dores. Nesse processo de reconstituição do sujeito, ressalta-se a necessidade de conservar aquilo que se é essencialmente, ser "fiel a si mesma", considerando também suas memórias traumáticas e as dores que lhe causam, uma vez que elas também são constituintes de sua identidade. Apesar do auxílio que os sujeitos com quem a personagem interage podem proporcionar, essa reconstituição identitária e, simultaneamente, a recuperação do corpo traumatizado, são processos essencialmente individuais, como pode ser percebido no seguinte trecho:

ia ter que se levantar, sozinha, sem muletas de remédios, enfrentando o risco, pagando para ver. Quando chegasse o momento em que se sentisse suficientemente forte, com um mínimo de segurança para ter um ponto de apoio onde se firmar e se converter em alavanca de si mesma" (MACHADO, 1988, p. 237). 
Ao longo do romance percebe-se que, apesar da necessidade que a protagonista sente de narrar suas memórias, está momentaneamente com dificuldades por conta do distúrbio e por causa das dores que as lembranças ainda lhe trazem. Essa dificuldade de transpor em palavras as memórias traumáticas também poderia relacionar-se ao que Seligmann-Silva (2013, p. 133) chama de oscilação entre uma necessidade e uma impossibilidade: "necessidade de narrar e a impossibilidade de esgotar com palavras suas vivências". Nessas situações, é como se existissem descontinuidades entre o pensamento e a linguagem, podendo gerar silêncios e omissões. No romance de Machado, é por meio da tentativa de escrita de uma peça de teatro que Lena procura elaborar, lembrar e esquecer seus traumas. No entanto, vive esse conflito entre a necessidade e a impossibilidade de narrar, tanto pelo distúrbio e pelo sofrimento que rememorar lhe provoca, física

Memórias, dorese traumas e psicologicamente, quanto pela dificuldade de transpor suas dores e suas memórias através das palavras:

\footnotetext{
O problema todo é que não tinha como compartilhar esse mundo interior sem as palavras. E as palavras fugiam dela com a doença. Ou com os remédios que impediam que o chão fugisse. Era como se em algum momento ela tivesse que escolher entre perder o prumo e perder a palavra (MACHADO, 1988, p. 128).

Era uma questão - de qualquer modo, nada simples - de conseguir mergulhar no mundo com uma percepção plena, elaborar isso internamente, jogar tudo para fora de novo de uma forma bela. Para isso, trabalhar muito [...]. Mas Lena achava que, com as palavras, tudo fica de certa maneira mais complicado (MACHADO, 1988, p. 160).
}

Ao mesmo tempo, a personagem manifesta também uma preocupação com a memória, tanto individual quanto coletiva, refletindo sobre a importância de recordar esse passado traumático, de dar seu testemunho através da literatura, de falar sobre as dores, como uma forma de evitar o esquecimento e a repetição desse tipo de violência no presente e no futuro. Por meio da voz narrativa, vislumbra-se como o simples ato de pensar sobre esse passado lhe causava sofrimento: “até hoje, Lena não podia pensar nisso sem sentir um aperto no peito, um nó na garganta, uma raiva impotente, uma dor inenarrável, uma vergonha imensa de fazer parte de uma nação em que coisas desse tipo aconteceram e nunca foram punidas" (MACHADO, 1988, p. 98). 
Em Tropical sol da liberdade, a escrita constitui-se como um "território de liberdade pessoal" (MACHADO, 1988, p. 43). No romance, a personagem busca apropriar-se da narrativa e do discurso como um espaço de proteção, de libertação e de autonomia, assim como um lugar possível para a reconstrução de si como sujeito, como se vê nos seguintes Camila fragmentos: "ela queria esculpir e cinzelar a pedra bruta da linguagem Marchesan de todo dia [...] para construir uma morada que ajudasse a proteger a toCargnelutti

Marcus dos" (p. 43); "sobretudo para si mesma, morada que fosse um território seu, sem invasões" (p. 43); "um dique contra a invasão, delimitando um território seu, de liberdade pessoal" (p. 43). Ganha relevo a importância da palavra para a protagonista, configurando-se como um recurso fundamental para construir-se como sujeito e, portanto, essencial como um meio de libertação, emancipação e empoderamento feminino. Essa situação também fica explícita no trecho a seguir, em que Lena consegue enfrentar o autoritarismo do médico que fora consultar por conta de seu distúrbio:

[Orgulhosa] por não ter calado a boca diante do autoritarismo arrogante do professor. Era a primeira vez, em semanas, que conseguia enfrentar alguém [...]. Não, alguma coisa lhe dizia que doença e morte era deixar que alguém a silenciasse e cassasse sua palavra e seu desejo, como o professor queria fazer. Afinal, era disso que estava enferma, era isso que tanto a incomodava, era para isso que buscara tratamento. Sentia que estava certa. Não era o queijo, era a fala. Viver sem a palavra não interessava (MACHADO, 1988, p. 54).

No fragmento acima, também se pode observar a necessidade que Lena sente de construir seu próprio discurso, de não se deixar silenciar por conta de autoritarismos e de recusar o papel de subordinação historicamente reservado às mulheres, questionando, enfrentando e desconstruindo discursos patriarcais conservadores. Tropical sol da liberdade, valendo-se do discurso ficcional de autoria feminina, apresenta não somente outras perspectivas sobre o período ditatorial, mas também leituras e visões sobre a condição da mulher nesse processo histórico. O romance de Ana Maria Machado vai ao encontro do que Navarro (1995, p. 52) fala sobre a literatura de autoria feminina na América Latina: “essas narrativas apresentam uma nova visão da mu- 
lher que, através da força da palavra escrita, ou através de uma forma contestadora de atuação no mundo, subverte os padrões comportamentais tradicionalmente exigidos ao 'segundo sexo"'. Dessa forma, tanto a autora quanto a própria protagonista do romance, bem como sua mãe, subvertem a representação tradicional do gênero feminino, construindo mulheres como sujeitos de seus próprios discursos, de suas identidades e de suas histórias.

\section{Considerações finais}

Articulando conceitos dos estudos de gênero e das discussões sobre hisMemórias, tória e memória, nesse estudo também partimos da compreensão da dorese literatura como uma produção estético-cultural permeada de historicidade e por subjetividades. Assim, temos em mente que também o valor traumas é uma categoria histórica e sempre resultante de um embate, de um processo de construção de hegemonia. É importante acentuar que os critérios determinantes do valor e da beleza de uma obra, constituindo os "universais", têm origem em posicionamentos e visões sociais hegemônicas, consideradas representativas da universalidade e selecionadas a partir de uma suposta neutralidade ou imparcialidade científica. Esses "universais", por sua vez, possuem um recorte de gênero bem definido - o ponto de vista considerado "universal" foi construído a partir de uma ótica masculina e vai ao encontro do que escreveu Beauvoir (1970, p. 183): “a representação do mundo, como o próprio mundo, é operação dos homens; eles o descrevem do ponto de vista que lhes é peculiar e que confundem com a verdade absoluta".

Nesse contexto, Tropical sol da liberdade e a literatura de autoria feminina, as teorias e a crítica feminista, em geral, possuem um importante potencial como construtoras de saberes desestabilizantes. Assim, possibilitam a emersão de uma pluralidade de vozes e de sujeitos e contribuem para desconstruir a pretensão teórica de produção de um conhecimento ou de uma história "oficial", "verdadeira", "neutra", "inquestionável" ou "universal". Nesse sentido, surge também uma abertura maior para a construção de literaturas, memórias e histórias "não oficiais", contadas a partir de grupos socialmente minoritários, em uma relação de coexistência com discursos "oficiais" - como é o caso do romance de Ana Maria Machado, que procura trazer outras versões a respeito do período ditatorial brasileiro a partir de um recorte de gênero. Na contramão das teorias supostamente objetivas e científicas, os 
estudos feministas assumem a rica potencialidade das experiências e das memórias femininas e reafirmam a importância da subjetividade e da política, tanto no processo de criação literária, quanto no processo de análise crítica.

Nesse estudo, abordamos também como o testemunho pode maCamila nifestar-se de diversas formas e, particularmente, por meio da consMarchesan trução literária, entremeando elementos fictícios e factuais e inter-reCargnelutti

Marcus lacionando a linguagem poética e a linguagem referencial. Além disso, esses escritos constituem-se a partir da compreensão de que existem múltiplas formas de ver e narrar os acontecimentos, as relações humanas, as histórias. Ainda que cada forma de expressão tenha suas particularidades, Seligmann-Silva (2013) destaca que o testemunho deve ser considerado e reconhecido como um exercício permanente para a construção de uma política de memória, de maneira a evitar a repetição da violência. Nesse sentido, o testemunho - e, especificamente, na forma literária - não deve ser entendido apenas como uma mera rememoração do passado, mas, sim, como construção e reconstrução no presente da injustiça e da opressão sofridas.

Em Tropical sol da liberdade, analisamos como a personagem principal, Lena, que passou por eventos traumáticos durante a ditadura civil-militar brasileira, tenta apropriar-se da palavra, apesar das dores que esse processo de rememoração dos traumas lhe causa. Essa apropriação acontece, na narrativa de Ana Maria Machado, na forma de escrita de uma peça teatral a partir de testemunhos de outras mulheres exiladas latino-americanas e configura-se, como vimos na análise, como uma maneira de elaborar, narrar e externar seu passado traumático. Essas lembranças do passado, ao mesmo tempo em que constituem sua memória individual, também fazem parte das experiências de outras mulheres exiladas por conta de suas ideologias políticas em contextos ditatoriais. No enredo, a elaboração dessas memórias faz parte da própria reconstrução identitária da personagem e relaciona-se à necessidade de lembrar e, simultaneamente, de esquecer o trauma. Por fim, em Tropical sol da liberdade, esse processo de apropriação da palavra e da escrita pela protagonista representa, ainda, uma forma de narrar outras histórias, baseadas em experiências femininas a respeito da ditadura civil-militar brasileira, constituindo-se também como espaços político-literários de memória e de resistência feminina. 


\section{REFERÊNCIAS}

ADORNO, Theodor. Posição do narrador no romance contemporâneo. In: ADORNO, Theodor. Notas de literatura I. Trad. Jorge de Almeida. São Paulo: Duas Cidades; Ed. 34, 2003. p. 55-63.

ALÓS, Anselmo Peres (Org.). Poéticas da masculinidade em ruínas: o amor em tempos de AIDS. Santa Maria: PPG-L Editores / CNPq, 2017a.

Memórias, dorese

ALÓS, Anselmo Peres. Leituras a contrapelo da narrativa brasitraumas

leira: redes intertextuais de gênero, raça e sexualidade. Santa Maria: PPG-L Editores / CNPq, $2017 \mathrm{~b}$.

ALÓS, Anselmo Peres. A letra, o corpo e o desejo: masculinidades subversivas no romance latino-americano. Florianópolis: Mulheres, 2013.

ALÓS, Anselmo Peres. Literatura e intervenção política na América Latina: relendo Rigoberta Menchú e Carolina Maria de Jesus. Cadernos de Letras da UFF, Niterói, n. 38, p. 139-162, 2009. Disponível em: <http://www.uff.br/cadernosdeletrasuff/38/artigo8.pdf>. Acesso em: 3 dez. 2018.

BEAUVOIR, Simone de. 0 segundo sexo: fatos e mitos. Trad. Sérgio Milliet. 2. ed. São Paulo: Difusão Europeia do Livro, 1970.

BRAUNSTEIN, Néstor A. Sobrevivendo ao trauma. Trad. Marylink Kupferberg. [s. d]. Disponível em: <http://nestorbraunstein.com/escritos/index>. Acesso em: 2 dez. 2018.

BURGOS, Elizabeth; MENCHÚ, Rigoberta. Me llamo Rigoberta Menchú y así me nació la conciencia. México: Siglo Veintiuno Editores, 1985.

DALCASTAGNÈ, Regina. 0 espaço da dor: o regime de 64 no romance brasileiro. Brasília: Universidade de Brasília, 1996. 
DE MARCO, Valeria. A literatura de testemunho e a violência de Estado. Lua Nova, São Paulo, n. 62, p. 45-68, 2004. Disponível em: <http://www.scielo.br/pdf/ln/n62/a04n62>. Acesso em: 5 dez. 2018.

LAUB, Dori. Truth and testimony: the process and the struggle. In: Camila CARUTH, C. (Org.). Trauma: explorations in memory. Baltimore: Marchesan Johns Hopkins University Press. p. 61-75.

Cargnelutti

LEVI, Primo. É isto um homem. Rio de Janeiro: Rocco, 1988.

Marcus

Vinicius Reis

MACHADO, Ana Maria. Tropical sol da liberdade. Rio de Janeiro: Nova Fronteira, 1988.

NAVARRO, Márcia Hoppe. Por uma voz autônoma: o papel da mulher na história e na ficção latino-americana contemporânea. In: NAVARRO, Márcia Hoppe (Org.). Rompendo o silêncio: gênero e literatura na América Latina. Porto Alegre: Editora da Universidade/ UFRGS, 1995, p. 11-55.

PRATT, Mary Louise. Mulher, literatura e irmandade nacional. In: HOLLANDA, Heloísa Buarque de (Org.). Tendências e impasses: o feminismo como crítica da cultura. Rio de Janeiro: Rocco, 1994, p. 127-157.

ROSENFELD, Anatol. Reflexões sobre o romance moderno. In: ROSENFELD, Anatol. Texto/contexto. São Paulo: Perspectiva, 1969. p. 73-95.

SCHMIDT, Rita Terezinha. Em busca da história não contada ou: o que acontece quando o objeto começa a falar? Letras, Santa Maria, n. 16, p. 183-196, jan./jun. 1998.

SELIGMANN-SILVA, Márcio. Direito pós-fáustico: por um novo tribunal como espaço de rememoração e elaboração dos traumas sociais. In: SARMENTO-PANTOJA, Augusto; CORNELSEN, Élcio Loureiro; SARMENTO-PANTOJA, Tânia (Org.). Literatura e cinema de resistência: novos olhares sobre a memória. Rio de Janeiro: Editoria Oficina Raquel, 2013, p. 123-138. 
SELIGMANN-SILVA, Márcio. Grande Sertão: Veredas como gesto testemunhal e confessional. Alea, Rio de Janeiro, v. 11, n. 1, p. 130147, jan./jun. 2009. Disponível em: <http://www.scielo.br/pdf/alea/ v11n1/v11n1a11.pdf>. Acesso em: 5 dez. 2018.

SELIGMANN-SILVA, Márcio. Narrar o trauma: a questão dos testemunhos de catástrofes históricas. Psicologia Clínica, Rio de Janeiro, v. 20 , n. 1, p. 65-82, 2008.

UMBACH, Rosani Úrsula Ketzer. Memórias autobiográficas em narMemórias, dorese rativas pós-ditatoriais. Letras de hoje, Porto Alegre, v. 48, n. 4, p. traumas 476-483, out./dez. 2013.

UMBACH, Rosani Úrsula Ketzer. Memórias da repressão e literatura: algumas questões teóricas. In: UMBACH, Rosani Úrsula Ketzer (Org). Memórias da repressão. Santa Maria: UFSM, PPGL-Editores, 2008, p. 11-22.

VIEZZER, Moema; BARRIOS, Domitila. Si me permiten hablar: testimonio de Domitila, una mujer de las minas de Bolivia. México: Siglo Veintiuno Editores, 2005. 
